\title{
The relationship between outdoor temperature and the frequency of falls among the elderly in Finland
}

\author{
H Luukinen, K Koski, S-L Kivelä
}

Information about the relationship between climatic factors and falls is limited. The available evidence suggests that among elderly women the risk of falling indoors increases during cold weather because of hypothermia that results from inadequate heating. ${ }^{1}$ We investigated this relationship by studying the incidence rates of indoor and outdoor falls among elderly people living at home relative to outdoor temperature.

Methods: All people aged 70 years or over and living at home $(n=1016,96 \%$ participated $)$ in five rural municipalities around the city of Oulu were prospectively followed up from 1 January 1991 to 31 December 1993, as described previously. $^{2}$ The mean (SD) age was $76.4(5 \cdot 0)$ years and $62 \%$ of the participants were women. Over the three years, 126 participants died and 67 moved to long term institutional care or to other districts. At the end of the follow up, 787 persons were still living at home.

All falls, including those that did not result in injury, were recorded by the participants in a diary immediately after the incident. Every participant was phoned once in three months to determine the frequencies, times, places, circumstances, causes, and consequences of falls. To complete the recording of injurious falls, relevant hospital and health care medical records were examined at the end of 1991, 1992, and 1993. The daily mean temperatures during the follow up were provided by the local meteorological research station. The mean (SD) temperature during the three year follow up was $3 \cdot 0^{\circ} \mathrm{C}\left(9 \cdot 2 ; \min -24^{\circ} \mathrm{C}, \max +23^{\circ} \mathrm{C}\right)$.

The person-time and incidence rates of falls were calculated, and calculations of indoor and outdoor falls were done for the quintiles of degrees of outdoor temperature. The $95 \%$ confidence intervals $(95 \% \mathrm{CI})$ were determined by Poisson distribution.
Numbers incidence rates (no/1000 person years) and 95\% confidence intervals (95\% CI) of indoor and outdoor falls in relation to outdoor temperature among the home-dwelling elderly

\begin{tabular}{|c|c|c|c|c|}
\hline \multirow{2}{*}{$\begin{array}{l}\text { Outdoor } \\
\text { temperature }\left({ }^{\circ} \mathrm{C}\right)\end{array}$} & \multicolumn{2}{|c|}{ Indoor falls } & \multicolumn{2}{|c|}{ Outdoor falls } \\
\hline & No & Incidence $(95 \%$ CI) & No & Incidence $(95 \% \mathrm{CI})$ \\
\hline $\begin{array}{l}<-20 \\
\geqslant-20<-10 \\
\geqslant-10<-0 \\
\geqslant 0<10 \\
\geqslant 10\end{array}$ & $\begin{array}{r}4 \\
46 \\
221 \\
241 \\
174\end{array}$ & $\begin{array}{l}573(158,1412) \\
236(173,315) \\
279(244,318) \\
265(233,300) \\
237(203,275)\end{array}$ & $\begin{array}{r}5 \\
33 \\
180 \\
209 \\
127\end{array}$ & $\begin{array}{l}774(227,1614) \\
169(117,238) \\
227(196,263) \\
230(199,263) \\
173(144,206)\end{array}$ \\
\hline
\end{tabular}

Results: A total of 1299 falls took place during the follow up, corresponding to an incidence rate of 492 falls $/ 1000$ person years (PY) $(95 \%$ CI 465,520). The exact time of the fall was not available in 50 falls; in 10 cases data on the place of the fall were not available.

For the remaining 1239 falls, the incidence rates of indoor and outdoor falls were 260/ $1000 \mathrm{PY}(95 \% \mathrm{CI} 240,280)$ and $210 / 1000 \mathrm{PY}$ $(95 \%$ CI 193, 229) respectively. The incidence rate of outdoor falls where the temperature was below $-20^{\circ} \mathrm{C}$ was higher $(774 / 1000 \mathrm{PY}(95 \%$ CI 227,1614)) than that for outdoor falls when the temperature was $+9^{\circ} \mathrm{C}(173 / 1000 \mathrm{PY}(95 \%$ CI 144,206)) (table).

Discussion: The rates of indoor and outdoor falls reported here are similar to previous findings. ${ }^{3}$ Our result that the incidence of outdoor falls was higher during the periods of extreme cold than during warmer periods may be a chance occurrence. There is little variation in the rates of falls in relation to temperature among elderly Finns. This finding is not consistent with those of Campbell et al in New Zealand, ${ }^{1}$ but agrees with that of Jacobsen $e t$ al, who found no association between the changing weather conditions and the risk of hip fractures. ${ }^{4}$

The non-dependence between cold weather and the frequency of indoor falls suggests that elderly Finns are protected against hypothermia because they live in adequately heated houses. The increased risk in elderly Finns of falling outdoors because of winter conditions is obviously compensated for by proper clothing, maintenance (ie gritting) of the pavements, and the reduced frequency of going out.

This study shows that the tendency of cold weather to increase the risk of falling among elderly people can be prevented and should therefore be given serious attention, especially in countries that do not take the same sort of comprehensive precautions against freezing as is the case in Finland.

This work was funded by grants from the Academy of Finland and the Ministry of Social Affairs and Health.

\footnotetext{
1 Campbell AJ. Falls, elderly women and the cold. Gerontology 1988;34:205-8.

2 Luukinen H, Koski K, Hiltunen L, Kivelä S-L. Incidence rates of falls in an aged population in northern Finland. $\mathcal{f}$ Clin Epidemiol 1994;47:843-50.

3 O'Loughlin JL, Boivin J-F, Robitaille Y, Suissa S. Falls among the elderly: distinguishing indoor and outdoor risk factors in Canada. F Epidemiol Community Health 1994;48:488-91.

4 Jacobsen SJ, Sargent DJ, Atkinson EJ, O'Fallon WM, Melton LJ. Population-based study of the contribution of weather to hip fracture seasonality. Am $\mathcal{F}$ Epidemiol 1995;141:79-83.
} 